REVISTA ANDALUZA DE ANTROPOLOGÍA.

NÚMERO 7: GITANOS/ROMA:AUTO-PRODUCCIÓNCULTURAL Y CONSTRUCCIÓN HISTÓRICO-POLÍTICA SEPTIEMBRE DE 2014

ISSN 2174-6796

[pp. 62-80]

http://dx.doi.org/10.12795/RAA.2014.i07.04

Fecha de Recepción: 10-03-2014

Fecha de Aceptación: 15-04-2014

\title{
CUESTIONES DE CREATIVIDAD CULTURAL: NOTAS EN TORNO A LOS GITANOS MEXICANOS DE ORIGEN IBÉRICO
}

\section{David Lagunas \\ Universidad de Sevilla}

\section{Resumen.}

La tentativa de este texto es contribuir a la ampliación del discurso sobre la creatividad cultural de los gitanos, y la antropología social en general, aportando cuestiones que son importantes para el presente y el futuro de los estudios sobre gitanos. Ello con el fin de presentar algunas pistas de investigación y orientaciones conceptuales que recapitulan los hallazgos de anteriores etnografías realizadas con grupos gitanos. Para ello realizo un análisis y avance sobre las formas particulares de creatividad cultural entre los calós mexicanos en relación a sus estrategias económicas de reproducción.

\section{Palabras Clave.}

Gitanos, creatividad, México, performance, reproducción.

\section{Abstract.}

The attempt of this paper is to contribute to the expansion of the discourse on cultural creativity of the Gypsies, and social anthropology in general, bringing issues that are important for the present and future studies of Gypsies. This in order to present some clues of research and conceptual orientations that recapitulate the findings of previous ethnographies conducted with Gypsy groups. To this end I analyze and advance some 
particular forms of cultural creativity among Mexican Calós regarding their economic strategies of reproduction.

\section{Keywords.}

Gypsies, creativity, Mexico, performance, reproduction.

Señalaba Okely (1997) que el poder de algunas ideas sobre otras depende del momento histórico que provee el contexto para que estas ideas florezcan. En sintonía con la idea de Barth sobre el focus en el límite en lugar de los contenidos, el compromiso entre un adentro y un afuera es un aspecto clave en el abordaje de los grupos roma: por un lado, la fluidez antropológica de los sistemas roma ha sido una cuestión compleja a la hora de fabricar una representación científica coherente; por el otro, los principios políticos de cada Estado así como la coyuntura "mental" del momento inciden en la reformulación y reconstrucción permanente de los sistemas antropológicos roma (Asséo $\left.{ }^{1}\right)$.

Disponemos del apoyo en la tradición de los estudios roma de excelentes monografías sobre los roma debido a que no muestran diferencias epistemológicas respecto a etnografías anteriores. Las buenas monografías no muestran diferencias epistemológicas respecto a las etnografías anteriores, y ello sigue siendo la mejor garantía de una buena etnografía, es decir, su reiteración frente a cualquier planteamiento panfletario. Es significativo que determinados grupos roma, con etnografías continuadas (aunque relativamente escasas y dilatadas en el tiempo), posean una estética tan importante. A ella han acudido frecuentemente poetas, pintores, músicos y otros creadores ${ }^{2}$, lo cual indica una correspondencia entre la creatividad cultural y la creatividad estética. Apreciar la riqueza de las culturas roma es un experiencia, en ocasiones, cercana al "gusto": "es como" una percepción estética (no "es" una percepción estética). Así, la relación entre los significantes, lo icónico y otros significantes se halla latente en la comparación cultural, e implica para el etnógrafo hacer de espejo de todo ello, no buscando los significados a la manera del simbolismo, sino la sintaxis. Puede pensarse una analogía entre las formas artísticas y la antropología, aunque una cosa no capacita para la otra.

Los grupos roma poseen una estética muy importante, explotada en el cine, la televisión, la música y la literatura. En líneas generales, la apropiación de los gitanos por la antropología como un objeto de conocimiento, encerrados dentro del entramado antropológico y también en el entramado fotográfico, tanto literal como metafóricamente, se llevó a cabo con el soporte de los instrumentos de representación (cine, literatura, fotografía)

1. Comunicación personal.

2. En relación a los gitanos españoles, cabe destacar a los pintores Isidre Nonell (Lagunas, 2005), Julio Romero de Torres y Zurbarán, la novela Carmen de Merimée -y la ópera de Bizet-, Cervantes, así como la poesía de Federico García Lorca (Lagunas, 2010). 
y los propios sistemas de registro de los científicos sociales y amateurs. La perspectiva antropológica e histórica de los gitanos se despliega a partir de estudios de síntesis de tipo intelectual, estética, social y moral. A partir del estudio y crítica de los sistemas intelectuales escritos de la literatura y las artes gitanas y la categorización política de los gitanos, es posible ver los fantasmas, es decir, la fantasmagoría de los sistemas de representación (Asséo $\left.{ }^{3}\right)$.

El momento actual está siendo muy fértil en cuanto a la producción de etnografías comprehensivas sobre los roma en referencia a diversos campos y facetas, con trabajos de campo extensos y con gran observación y participación. En este sentido, el panorama de los estudios sobre los roma ha ido cambiando progresivamente. En el plano académico, destacan las controversias más recientes, impulsadas por Asséo, sobre la cuestión del "nomadismo" roma, considerando que en la actualidad dicho concepto ya ha sido rebasado, siendo inútil la aplicación de este paradigma, y substituido por otros términos, como "movilidad", "circulación". Del mismo modo ocurre con los sistemas de parentesco, dominados durante varias décadas por paradigmas periclitados, como la teoría de linajes (ver Piasere, 1991; Williams, 1984; Lagunas, 20054), así como la inclusión de los roma entre los grupos giróvagos y peripatéticos ${ }^{5}$ (Rao, 1987; Piasere, 1995). Stewart (2010) critica las nociones de grupo étnico, etnicidad y la atribución de la condición de "grupo" a los roma. El cuestionamiento de la "grupalidad" es parte de las críticas a las ilusiones y consecuencias de la ideología diferencialista y sustancialista de la identidad cultural (ver Friedman, 2001, y la crítica a la cultura como sustancia; Herzfeld, 2001; Brubaker, 2004, frente al "grupismo"; Cooper, 2005; Gallissot, 2000, sobre la "identificación" como proceso). A ello podemos añadir que la antropología política nunca se ha interesado por los contextos roma, sólo a través de referencias puntuales a instituciones como la $k_{r i s^{6}}$ (ver Liégeois, 1973); esto es, como si se reclamara a los roma que son incapaces de representarse como cultura subalterna (ver la crítica de Piasere, 1991), pero, al menos, tienen la kris... lo cual esconde una visión esencialista: "los roma no tienen religión ni nación... pero sí la kris" (Asséo7). El efecto de todo ello es "primitivizar" a los roma, creyendo descubrir una relación de poder total que aplastaría las diferencias. Si un

\section{Comunicación personal.}

4. En relación a los roma, Piasere (1994:21-22) se refería hace dos décadas a un gueto académico invisible que controlaba la producción gitanológica y que se alarmaba cada vez que un antropólogo no conocido violaba su territorio, no aceptaba las reglas tácitas y la tutela de la élite, independientemente de los contenidos de sus ideas.

5. Houseman (1994:13), en lugar del grado de peripatetismo efectivo prefiere emplear la idea de circulación como el leitmotiv de las representaciones y experiencias roma: "la movilidad, presente o pasada, real o virtual, aparece como un aspecto constitutivo de las identidades gitanas".

6. La kris es una corte o tribunal tradicional para la resolución de conflictos que se observa en grupos rom vlax del sudeste de Europa.

7. Comunicación personal. 
marxista cree descubrir en las sociedades primitivas ese modelo total de dominación en el modo de producción, en nuestro caso se trataría del imaginario poder absoluto de los sistemas autónomos legales (ver Weyrauch \& Bell, 1993) de dominación "patriarcal" como ideología dominante integradora, a lo Parsons. Por tanto, se asume que más allá de la kris y la integración no hay fisuras ni fallas del sistema. En este sentido, la creencia en la kris y otros símbolos culturales también puede ser una manera de vehicular y transmitir una identidad a un extranjero (con un énfasis inexistente en el interior del grupo), así como ejemplo de un respeto a un símbolo de identidad propia y por ello defendido, sin que aparezcan voces discordantes.

Así, paradójicamente, respecto a las comunidades roma nos hallamos ante dos extremos. Por un lado, históricamente han sido objeto de grandes monografías, aunque en número relativamente escaso en comparación a la fuerte presencia demográfica de los roma en los países europeos, y que han fundamentado el conocimiento científico sobre las comunidades roma. En cambio, la posición política y condición histórica de estas comunidades las han hecho especialmente aptas para ser el objeto de la formación y entrenamiento de jóvenes antropólogos así como para los profesionales del entorno sociológico, educativo y asistencialista (ver la crítica de Piasere, 1991).

¿Quiénes son los roma? Es una pregunta difícil de responder pues nos topamos con una definición, no indefinida, pero sí politética (Piasere, 1995). En primer lugar es un nombre histórico y externo que permite evocar la variedad de nombres existentes de grupos diversos entre sí. Dado que nos encontramos con una escasez crónica de traducción de lo interno, el modo de vida -de estar en el mundo-, cultural y sociológicamente contingente y en constante recreación de los roma, ha dado lugar a teorías y modelos que reflejan que han sido buenos para pensar simbólicamente, buenos para discriminar políticamente ${ }^{8}$ pero "indigestos" para pensar antropológicamente (ver Piasere, 1994). Asséo ${ }^{9}$ lamentaba que las investigaciones científicas en torno a los roma coexistan con un discurso mediático fantasmático y las elaboraciones populares estereotipadas, de forma que no existe correlación entre lo erudito y científico y la producción de un

8. Existe una amplia literatura a disposición del lector respecto a la discriminación y persecución de los gitanos que se inicia con su llegada a Europa y culmina con el apocalipsis del holocausto nazi. Para acercarse al tema puede consultarse Fraser (2005) y en específico San Román (1994) sobre los gitanos españoles.

9. Comunicación personal. 
discurso de autoridad ${ }^{10}$. La "indigestión" antropológica respecto a los roma se refleja en diversos planos como el empleo de teorías de segunda mano (Piasere, 1991; 2004) o, como Williams (1994) señalaba, la dificultad de la antropología para encajar en los marcos establecidos la fuerza singular de los roma y la ignorancia de sus contribuciones a la disciplina antropológica.

El problema es, desde este punto de vista, de proyección personal: los roma concebidos como arcaicos y renuentes al cambio, como un grupo marginal que a su vez genera una influencia muy marginal en la reflexión antropológica. Estos problemas aparecen porque los diversos grupos roma no están en igualdad de condiciones, considerándose el estudio de los roma, al igual que el de los pueblos primitivos (categoría hoy en desuso) en el siglo XIX, como una barbarología. Así se ha hecho característica habitual lo que es sólo extraordinario (por ejemplo, el canibalismo entre los pueblos primitivos; el nomadismo, hoy, entre los roma). Esto último sería asimilable al caso de los campos de concentración en Europa durante la II Guerra Mundial, cuya referencia resulta injusta para explicar metodológica y políticamente las circunstancias de la sociedad europea; la horrible barbarie nazi no es característica de la civilización europea sino que es excepcional -si bien, en circunstancias similares hipotéticamente podría volver a ser característica. Un ejemplo paradigmático de ello es la obra de Pierre Clastres dedicando demasiadas páginas a referirse a esta interpretación, hablando de la normalidad de estos fenómenos (la guerra, el canibalismo,..) entre las sociedades primitivas, como si fuera propio de estos pueblos, cuando en realidad son las víctimas. Al igual que ocurre en la Historia, ello podría deberse a un problema de formación. Nos hallamos en una época como la actual en que hay un exceso de artículos de opinión y, más bien, una antropología basada en manuales científicos, la cual a su vez estaría muy influida por un periodismo científico.

Los problemas que plantean los grupos roma son imposibles de resolver desde cualquier aproximación ortodoxa. La ausencia de los rasgos típicos de una organización social e institucional que interesan a los etnógrafos como los grupos corporados de descendencia, la variabilidad en las creencias religiosas de los roma (católicos, evangélicos, ortodoxos, musulmanes, etc.), los sistemas de alianzas singulares y originales de cada comunidad local, la presencia de líderes con un poder difuso y la inmensa variedad de grupos cuya composición es fluida, convierte a los roma en un conjunto de sociedades intrínsecamente intratables. La gitanología ha construido vulgarizaciones que suponen una devaluación

10. Ello también ocurre en el seno de la sociología y antropología militante y objetivante, tanto desde el exterior como al interior de las comunidades. Por ejemplo, en relación a la promoción de líderes masculinos roma como representantes políticos y líderes de sus comunidades frente a la emergente visibilidad femenina, o más específicamente en la construcción del nacionalismo (ver Piasere, 1995; Okely, 1997:230-231, sobre la distorsión que crean algunos intelectuales no-gitanos en los 60 y 70 reivindicando una patria para los roma-Romanestan-) que contrasta con el escepticismo y falta de interés de las poblaciones roma. 
por la sucesión de términos negativos aplicados a los roma: No religión, No Estado, No territorio $^{11}$. En consecuencia, las proyecciones fantasmáticas se han basado en la deshistorización, des-nacionalización y pseudo-territorialización (ver Asséo, 1994; Piasere, 2004).

No obstante, de algo podemos estar seguros los investigadores: no todo el que mira otra cultura la niega o la devalúa. De hecho, la comprensión y la explicación pueden ser positivas o negativas ontológicamente. Las ciencias sociales han relacionado conocimiento con aspectos negativos ontológicamente, de forma que sabemos que nuestra epistemología ontológicamente no es negativa y eso, al menos, lo sabemos. A los antropólogos les interesa estudiar a los otros y ver los fenómenos de otra manera, sin negación ontológica o etnocidio a nivel político. Tanto la mutilación etnocida como la mutilación epistemológica se han realizado y es erróneo; por ejemplo, finiquitar epistemológicamente a los pueblos que Occidente ha asimilado, esclavizado o liquidado, entre ellos los roma.

Los roma han de existir puesto que sería absurdo que no existieran y negar, incluso, la antropología del etnocidio ${ }^{12}$. De ello se deriva que el sentido del funcionalismo, la teoría de linajes británica o cualquier modelo de abstracción se crea al observar a otros pueblos. Es un hecho que en el seno de la disciplina ha habido una cierta confusión entre los términos de "ontología” y "epistemología”: al afirmar o negar el conocimiento con ello afirmamos o negamos el "ser" de la cultura. Y a pesar de que la antropología haya encontrado especiales dificultades para digerir e integrar a los grupos roma en sus marcos explicativos, la mera constatación de las dificultades para comprender las culturas roma o cualquier otra cultura no descarta automáticamente la epistemología.

Con frecuencia se olvida que todo modelo antropológico debe más al pensamiento nativo que a las tradiciones académicas. Así ocurre con conceptos hoy aceptados en la academia como reciprocidad. No puede hablarse de proyecciones occidentales pues esta acusación supondría un empobrecimiento de la cultura de los roma y de cualquier "otro". La idea según la cual los elementos nativos estarían únicamente influidos por los sistemas culturales globales que envuelven a las comunidades locales roma implicaría una continuación del evolucionismo, postulándose que los roma (como los pueblos exóticos en el siglo XIX) no pueden influir en las sociedades modernas. Paradójicamente, a la vez que se remarca la importancia de la experiencia etnográfica, se niega lo que pasa en la etnografía: los roma (y los pueblos exóticos) no pueden influir intelectualmente;

11. Ello representa un peligro para las etnografías, con lo cual debe irse con prudencia ante los estudios en los que se halla un exceso de conceptos abstractos en lugar de descripciones precisas. Piasere (1996) lamentaba tanto la falta de experiencia directa como la experiencia mísera que ha dado lugar a miles de páginas en numerosos estudios sobre los roma de dudosa calidad.

12. Históricamente, el modelo español fue la asimilación cultural -etnocidio- (Piasere, 2004). 
toda idea abstracta ha de provenir de un autor o fuente occidental. Ejemplos de ello son Marc Augé y sus seguidores, así como Marcel Detienne, usuales articulistas de L'Homme, quienes han defendido una idea de atomización y singularización total, mediante la que, en apariencia, no resulta posible generalización alguna (un precedente de esto lo hallamos ya en el cínico heleno Diógenes), produciéndose una negación de los descubrimientos; en concreto estos autores han rechazado las mayor parte de los paradigmas existentes, postulando un funcionalismo vulgar (ya en su día anatemizado por el mismo Malinowski). Esta postura tiene su origen en una contradicción: la actual situación de defensa de un liberalismo encubierto, a la par que éste y sus males son en apariencia criticados.

Esta corriente se opone a las relaciones inmediatas y estrechas que, desde tiempos de Morgan -no olvidemos que éste estudió la liga de los iroqueses a fin de seguir su ejemplo-, la antropología mantiene con los nativos. En parte, esto se ha motivado por la reacción externalista de historiadores de la antropología como Stocking y, sobre todo, Kuper, quienes exclusivamente consideran la influencia exterior -ya Llobera defendió la necesidad de realizar un compromiso entre internalismo y externalismo (en ocasiones, la postura de Llobera, al defender la antropología como ciencia, también se ha movido en extremos).

Así, resulta una idea habitual del posmodernismo el rechazar esta influencia interna. La misma postura de negación de Kuper ante el linaje es adoptada por Schneider en referencia a los grupos corporados, desconfiando del trabajo de campo y postulando que tales conceptos sólo son una mera invención del antropólogo. Los roma no son ajenos a esta polémica. Un ejemplo de ello es Henry Sumner Maine. A mediados del siglo XIX Maine (1893:cap. V) negaba la posibilidad de que los pueblos primitivos (basados en el parentesco agnaticio -sociedades de estatus-) pudieran desarrollar un sistema de gran complejidad social (basadas en la autonomía del individuo -sociedades de contrato-), de forma que técnica y condiciones sociales debían resultar emparejadas. Encontrar formas de gran complejidad social en sociedades de gran pobreza material sólo podía deberse a que los miembros de este grupo antaño hubieran pertenecido a una poderosa clase, conservando como descendientes suyos estas formas. Uno de los ejemplos con los que se pretendía otorgar validez a esta hipótesis, con cierto peso hasta mediados del siglo XX en la gitanología, fue el de los roma. Así, se suponía que el origen de sus formas sociales había estado en algún punto remoto de la India en un ámbito en el que hubieran sido cortesanos, teniendo acceso a complejas formas de etiqueta social. El hecho de que el romaní se emparentara con el sánscrito, la lengua de los intelectuales y la tradición literaria hindú, apoyaba esta idea. Por motivos desconocidos estos grupos habrían tenido que exiliarse, conservando de su antigua situación tan solo su complicado ceremonial. 
Con esto se estaba negando la creatividad de los roma, como si estos hubieran copiado de una civilización superior sus modos de comportamiento ritual y de etiqueta.

Las ideas sobrela evolución dela ley yla sociedad indo-europea, estableciendo paralelismos entre la India contemporánea y la Europa antigua (Maine, 1900), hicieron que Maine criticara a Morgan -unas criticas sin embargo relegadas más tarde, al formar estos junto con Bachoffen una línea de ataque contra los planteamientos rupturistas del escocés McLennan. Aún cuando los tres primeros tenían hipótesis diferentes, su metodología era muy similar, a diferencia del caso de McLennan, quien postulaba un nacimiento violento de las formas sociales-. Maine (ídem) consideraba que las observaciones de Morgan sobre los sistemas de parentesco, así como entre los iroqueses, eran producto de su imaginación, de ahí que lo criticara por lo que consideraba su idealización. Al estudiar Morgan estos grupos indios halló un paralelismo entre su parentesco y el de los antiguos romanos, de ahí que calificara sus grupos corporados como gens. Maine se oponía. Hablar de gens entre americanos implicaba que estos debían ser descendientes de Rómulo. Si como en el caso indoamericano, raciología y otros elementos se oponían no podía realizarse la comparación [una de las principales contribuciones de Henry S. Maine es la de haber sido el primer autor de las ciencias sociales en realizar un análisis comparativo, utilizando para ello diferentes pueblos de pretendido origen indoeuropeo], de ahí la falsedad del argumento. Por otro lado, una de las escuelas del pasado siglo, el difusionismo, buscó una alternativa a esta solución, pero también negando la creatividad de los pueblos exóticos, planteando que estos pueblos habrían copiado de una civilización superior sus modos de comportamiento ritual y de etiqueta. Ello convierte a la obra de Henry Sumner Maine en uno de sus pilares fundadores.

Una critica que se puede hacer a la elaboración de Maine, y otras similares que le han seguido, es que, no se trata que "no se puedan conocer los otros" (Winch, 1994), sino que no agrada tal descripción. Se critica el que se vea a los otros como un noble europeo ${ }^{13}$, un estado o una situación que nosotros o hemos perdido o, simplemente, carecemos. La cuestión no se resuelve entre comprender y no comprender (Winch, 1994) sino en tomar en consideración cómo los antropólogos comprenden con unos intereses específicos y van al campo con intereses académicos, teóricos, políticos, etc. La cuestión, finalmente, no sería si es posible o no conocer a los otros como señala Winch (sean o no occidentales) y, por tanto, sólo nos quede convertirnos en un indígena más. Lo que ocurre es que, en ocasiones, el antropólogo detesta a los otros o bien los idealiza románticamente, alabando aquello que los occidentales han perdido (la nostalgia del primitivo).

13. En Lagunas (2005) señalaba en este sentido que la preferencia matrimonial entre gitanos catalanes se basaba en la ideología de la sangre pura, pues el matrimonio endogámico hacía la raza más pura, limpiando la sangre, como forma de distinguirse de otros grupos gitanos no-catalanes. Esta ideología se emparenta con la propia de la nobleza europea de sangre azul emparentada con el rey, que utilizaba una retórica del parentesco para distinguirse de la nobleza recién llegada. 
Es obvio que si la antropología trata de la existencia de otras culturas no puede concluir estas otras culturas. Habitualmente en la disciplina se han revelado las influencias, imposiciones, represiones, proyecciones y dominaciones de los antropólogos y de la sociedad que representan a los sujetos estudiados en las sociedades no-occidentales. Sin embargo, la influencia de las sociedades locales sobre los antropólogos es un tema generalmente olvidado. La influencia de la cosmovisión nativa en el pensamiento antropológico supone una distinta apreciación de los fenómenos a partir de la educación desde prejuicios diferentes a los hegemónicos.

De hecho, se ha producido un saqueo occidental, extrayendo la identidad de origen de instituciones locales, de igual manera que el antropólogo está muy influido por los pensamientos locales. Con el saqueo, tanto de materias primas como de ideas e inteligencia primitiva, éstas serían travestidas y presentadas como nuestras. Montesquieu no tuvo ningún problema en aceptar que gran parte de sus ideas sobre democracia provenían de los escritores republicanos de la antigua Roma; de igual manera, y como él mismo reconoció, Schopenhauer se inspiró en el budismo para su concepto de la representación del mundo y de la voluntad de representación, influyendo en toda la fenomenología. Pero el saqueo generalmente no es reconocido, por ejemplo, en relación a las técnicas comerciales africanas aprendidas por los portugueses; los términos jurídicos de personalidad jurídica desarrollados por Maine a partir de las ideas bizantinas; o las ideas japonesas de fiscalidad (censos) y unidades imperiales que tras Roma se perdieron en Occidente y fueron aprendidas en Oriente por los misioneros dominicanos.

Williams (2011) señala que los roma han sido históricamente grupos que se han relacionado con los patrimonios de su entorno, recombinándolos, olvidándolos, conservándolos, gitanizándolos, desapegándose de ellos y de sus lugares de origen, sin perder necesariamente la conexión. Creo que Williams apunta hacia una serie de problemas mucho más amplios que resultan de constatar cómo la dinámica y la creatividad cultural pueden provenir de otras culturas, incluso cuando estas culturas -como los roma- adoptan nuestros conceptos, ideas, materiales y tecnologías para reinterpretarlos según su propia dinámica, provocando un desplazamiento en la dinamización. La clave reside en ver el interés que tienen estas otras culturas para observar que nuestra cultura también está construida a base de haber absorbido, usualmente de manera imperceptible, elementos de otras culturas. Estudiar otras culturas es entender elementos que en realidad no son de nuestra cultura sino que son importados, y por ello, al ser provenientes de otros contextos constituyen préstamos forzados al intentar conciliarlos con nuestra tradición. De forma que aquellas nociones que en nuestros países se han asociado a elementos muy ajenos, en ocasiones, son el resultado de experiencias extrañas que una vez que llegan a nuestra sociedad empiezan a transformarse según los términos de las necesidades occidentales, y viceversa. 
La opción metodológica pasa por conformarse con intentar revelar aquellos elementos de los roma que sean posibles con la idea de fabricar una representación coherente y hacer con ello a los roma interesantes e inteligibles. El academicismo guía pero no puede imponer criterios de selección. Un mapa te orienta en un paisaje, no te ayuda a conocer, a lo Wittgenstein; en sí, no se aprende la sensibilidad ni se aprende cómo ver una cultura, sino cómo llegar. La metodología empleada para el análisis de los roma debe limitarse constantemente, respondiendo a necesidades de conocimiento que gracias al estudio de estos y otros grupos los analistas disponen. Teniendo en cuenta la imperfección de la propia metodología, para que esto resulte útil debe tenerse en cuenta la crítica a toda tradición cultural: no existen culturas estáticas y las dinamizaciones entre los roma no son muy propias a la tradición, si bien, como señalábamos anteriormente, con frecuencia no se reconoce cuáles son los orígenes de la propia tradición, y tal vez por ello, despierta una xenofobia. Un ejemplo-de ello es el flamenco y los diversos estilos que incluye, entre ellos, el flamenco más propio de los orígenes gitanos ("juerga”) que emerge de manera informal en las bodas y celebraciones familiares, al igual como en el siglo XIX son moda algunas costumbres y elementos culturales de los gitanos (San Román, 1994:35) o contemporáneamente la rumba catalana que influyó decisivamente en rumberos míticos como el barcelonés Gato Pérez. También es el caso de otra dinámica cultural menos conocida como es la adopción por parte de los pachucos, jóvenes chicanos bilingües de los años 30 del siglo pasado en EEUU, del argot "caló" o "caliche" aprendido en los suburbios de la ciudad de México a finales del XIX, cuya filiación se conecta con los gitanos de España (García, 2005).

En efecto, irrita reconocer que la dinámica de determinadas instituciones, valores y prácticas culturales provienen de otras iniciativas y deben imitarse para que sobrevivan en el nuevo contexto. Cuando el principio de autoridad proviene de otra cultura, no de la propia y, además, éste es representado como inferior, es complicado reconocerlo. Una característica de la cultura Occidental es esta necesidad de saqueo, tanto de materias primas como de ideas e inteligencia primitiva, que luego son travestidas y presentadas como nuestras. La dinámica y creatividad cultural puede provenir de otras culturas, incluso adoptando nuestros conceptos para reinterpretarlos según su propia dinámica.

La esencialización y el ahistoricismo proyectados sobre las culturas roma, así como la representación negativa de su "etnicidad" y el mito construido sobre una Cultura roma en singular, forman parte de las dificultades en Occidente para apreciar a las diversas comunidades roma. Stewart (2010:4) señala que en el pasado la investigación académica sobre los roma fue marginal a causa de que muchos de sus practicantes eran folcloristas amateurs, quienes consideraban a los roma como parangón de un mundo perdido y como no-ciudadanos de los Estados-nación modernos, mientras que hoy todavía subsisten dos fuerzas contrastantes: la postura emocionalmente comprensible pero 
intelectualmente debilitante de subordinar a los roma a la cuestión de los "derechos humanos" y la dificultad de los académicos de abordar a un pueblo que no constituye un tipo de personas en el sentido que el Estado-nación define como tal. Esta apropiación fue una extensión de la política de conformación de los estados modernos políticamente centralizados, los cuales fueron posibles a partir de los dispositivos y mecanismos de homogeneización cultural de la población que pretendían administrar ${ }^{14}$. A partir de aquí aparecen los criterios que establecen la condición anormal de grupos sociales clasificados como minorías culturales como los roma, cultivando patrones conductuales y mentales considerados como no aceptables por el Estado y practicados por la mayoría.

El problema que revela Stewart no es exclusivo de los roma sino que ha afectado a la antropología desde sus inicios. El problema estratégico es el "problema del referente" - ¿en qué medida una estructura de ideas corresponde a una realidad?- (Holy \& Stuchlik, 2006: 160) aplicado a diferentes situaciones de la cultura en su comportamiento social. Ya Firth (1981) señalaba que el principal problema del funcionalismo era que constituía un modelo que en ningún momento correspondía al modelo que tenían las sociedades etnografiadas, sino que buscaba un modelo válido para las referencias cognitivas occidentales. El problema general de la antropología es construir modelos que en ningún momento corresponden al modelo que tiene la sociedad etnografiada, sino que se busca un modelo válido para las referencias cognitivas del contexto cultural del investigador social, imposibilitando la apertura cognitiva a nuevos elementos y temas. Así, el mayor problema -muy común en la literatura sobre los roma- es no revelar cuál es el punto de vista de los nativos ${ }^{15}$.

Sin embargo, es el tipo de creatividad cultural de los gitanos lo trascendente para el análisis y si esta creatividad puede dialogar con la etnografía de estos grupos ello es lo que determina la elección del antropólogo. Lo expuesto hasta ahora plantea la consideración acerca de los gitanos a partir de estilos: a) aquellos revelados en etnografías muy comprensivas (Piasere, 1985; Williams, 1984; Stewart, 1997b), b) de creatividad cultural que dialoga con la antropología, la sociología y la filosofía (ver Williams, 1996), c) de consideración de poblaciones, unas marginales otras con mayores equilibrios respecto a la sociedad global (Piasere, 2004; Fraser, 2005), d) de descubrimiento del crítico interno

14. En función de las relaciones de mutua hostilidad establecidas con las sociedades de su entorno y dependiendo de la posición política y socioeconómica de los diversos grupos roma, Piasere (2004) identifica tres modelos de relación: 1. modelo español: asimilación forzada y etnocidio, 2. modelo occidental: exclusión de la sociedad, y 3. modelo balcánico: esclavismo, no así de decaimiento demográfico. 15. Piasere (1999) ha invocado una "etnoantropología" para el estudio de las comunidades roma: cómo los diversos grupos perciben y aprehenden el mundo. 
(Leblon, 1990) y de los agentes ${ }^{16}$ de la historia; los actores gitanos son creadores de su propia historia, son sociedades con historia y tienen capacidad para hacer cambios.

En la reflexión que nos ocupa a continuación, el objetivo es conocer y explicar fenómenos particulares presentes entre los calós mexicanos y aspirar con ello a especular con las formas y las ideas. Para ello nos apoyaremos en la etnografía en curso y en concreto en un aspecto: el performance de las actividades económicas. Evitaremos utilizar un lenguaje demasiado hermético, aquel que sólo maneja el discurso y no sabe de las condiciones objetivas en que se desarrolla la vida, la sociedad y la cultura.

Consideramos que la reproducción cultural se encuentra imbricada con la reproducción económica. La idea de reproducción tiene resonancias funcionalistas y desde nuestro punto de vista particular se entiende mejor desde la presencia de tres dimensiones: 1. un programa (software) dinámico de reproducción que contiene en una forma compacta la información para generar los componentes de la cultura; 2. una interrelación (metabolismo) que permite utilizar recursos externos para sintetizar los propios componentes sociales y culturales a partir de los materiales del entorno (Gomes, 1998; Williams, 1996); 3. una estructura o barrera semipermeable que le sirve para distinguirse a sí mismo del entorno, y para filtrar (como una membrana) los materiales que le interesa importar de los que conviene mantener fuera o expulsar.

Quisiera avanzar algunas cuestiones preliminares por medio del análisis específico de un grupo de calós de origen español que habitan en la ciudad de México, esta vez, partiendo de una perspectiva dialógica y performativa, llevándola, más allá de su simple enunciación, a encararse con una realidad que la sobrepasa y que, usualmente, es generadora de problemas. El grupo de calós etnografiado se compone de alrededor de 150 individuos que se identifican como "gitanos españoles", y quienes residen en la

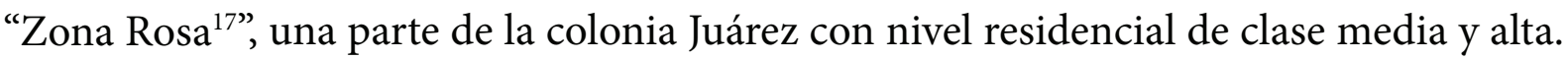
La comunidad local se formó hace aproximadamente 30 años, habiendo pasado sus miembros fundadores previamente por países como Brasil, Venezuela y Argentina. Se trata de una comunidad no cerrada, producida por inmigraciones que han dejado una composición de redes familiares en permanente construcción, permeabilizando toda la estructura social de tal sociedad.

La práctica de la vida material de los grupos roma, desde las ocupaciones a la modalidad de su presencia en el territorio, es el resultado de elecciones y valoraciones articuladas

16. Ver Firth (1975) sobre la noción de creatividad personal y la necesidad de escoger personalidades representantes de la cultura.

17. Ubicada al oeste del centro histórico de la ciudad de México es un vecindario con una intensa oferta de entretenimiento, vida nocturna y dinamismo comercial. Los calós se concentran alrededor de la plaza George Washington y las calles adyacentes. 
con la coyuntura, desplegándose de manera creativa (Piasere, 1999:21-35). La ocupación principal entre los calós es la venta ambulante. Los productos ofrecidos a los clientes potenciales son chaquetas (chamarras) de piel, complementos (gafas de sol, relojes, estilográficas, etc.), perfumes, ropa (camisas y pantalones), marcos de cuadros, cuberterías, mantelerías, colchas y otros productos. La estrategia de venta de los calós consiste en ofrecer al cliente ya sea un producto individual (chaqueta, complementos, etc.) o un conjunto de productos -lote- por un precio total ${ }^{18}$. Para ello, se dirigen a domicilios particulares, mercados, edificios públicos y de gobierno, empresas, pequeños y medianos comercios, y se desplazan a diversas zonas de la ciudad de México, su área metropolitana y el resto del país.

Nos centraremos en el performance como vía de conocimiento hermenéutica y como acción significativa en su descripción de proceso creador de cultura, en el cual operan el discurso, la presentación del yo y el manejo de la impresión (Turner, 1985: 182-187; Goffman, 1981). En términos de una fenomenología radical y en relación a la percepción sensible inmediata, los calós no se "fían" de los payos y cultivan, estructuralmente y de manera persistente, sentimientos de hostilidad, odio, miedo y envidia (Piasere, 1999, y los procesos de cismogénesis gaze/roma). La memoria del maltrato hacia los calós pesa ${ }^{19}$. Una muestra de ello en particular ocurrió cuando dos de las personas ancianas más reputadas de la comunidad aceptaron que las entrevistara para preguntarles acerca de las fechas de su llegada a México. La mayor parte de las palabras de los dos ancianos no fueron para explicar cuándo llegaron a México, dónde empezaron a vender, o cuáles fueron sus estrategias económicas, sino que emplearon todo su tiempo en describir de manera pormenorizada la arbitrariedad de los jueces y tribunales españoles y los abusos de los comisarios de policía y la guardia civil sobre los calós bajo el régimen franquista. Esto era, según ellos, el contexto que hacía de España un país invivible en la época de la posguerra, a diferencia de México donde encontraban la libertad negada en el país de origen. Los ancianos "recordaban" y como sujetos que recordaban "historizaban" su experiencia.

En primera instancia, la transacción comercial de la venta ambulante representa un ritual constitutivo de tipo regulativo en el sentido de que orienta y regula una actividad

18. La venta ambulante del lote fue un tipo de estrategia comercial realizada por los gitanos españoles e impulsada desde los años 50 con la mecanización del campo, alcanzando una gran importancia hasta los años 70. En la venta del lote el margen de beneficio es mayor y el tiempo de venta menor que si se tuviera que vender uno por uno todos los productos ofertados.

19. "No se trata de un problema de penetración mental, de austeridad etnocéntrica o de exotismo efectista. Es un problema de trato histórico. El trato entre los pueblos pesa y condiciona. La memoria de un mal trato o trato desconcertante conlleva una dosis de incomunicación. No se comprende a quien se trata o se ha tratado mal. Intentar comprender una civilización que ha estado sometida a la incomprensión y al avasallamiento moral de una Misión, de unos comerciantes o de unos colonos, viniendo de la civilización que ha infligido ese trato, es casi sólo una pretensión" (Terradas, 2004:26). 
práctica, remitiendo al estilo estético de la actividad y la cualidad de sus características diacríticas (Tambiah, 1995: 144). Stewart (1997a: 97) señala que la representación de la dominación de los gaze por parte de los rom vlach húngaros en las transacciones del mercado de caballos es un constructo ideológico que remite, por un lado, a una imagen de autosuficiencia por medio de la obtención de recursos de los payos (sin que se produzca una relación recíproca con ellos), y por otro, a la igualdad y el ethos del compartir. Así, el modelo cultural y la morfología social se interrelacionan de tal forma que posibilitan que cada individuo construya sus ideas sobre sí mismo y sobre el mundo a partir de la acción socio-simbólica, la cual es generadora de conciencia de identidad.

En este sentido, lo que singulariza a los calós mexicanos es el producto del tipo de intercambio, coyunturas sociales y contingencias históricas (Piasere, 2004) que proveen la aceptabilidad en el territorio mexicano. La combinatoria de los calós, la poética social, es el substrato de la creatividad cultural. Frente a este proceso social explícito, duro y discriminador, los calós juegan creativamente con los rótulos, los cuales son señales que a su vez representan ofensa y daño; el poder de manipulación de la realidad consiste en obviar un rótulo de identificación distintivo y conductual ("gitano"), el cual implica contenidos específicos (tradición, racismo, etc.). La reacción que se espera del payo como sujeto que recibe estímulos y reacciona frente a la información del acto comunicativo "perfecto", a la manera del interaccionismo simbólico de G. H. Mead, es una respuesta de entusiasmo y/o de sumisión.

Una de las técnicas más empleadas para estimular la motivación a la adquisición de las mercancías ofrecidas es, para los hombres, hacerse pasar por sobrecargo o piloto de aviación, $\mathrm{u}$ otros roles (por ejemplo, corresponsal del New York Times en Madrid). Las mujeres enfatizan su condición de ciudadanas españolas y negociantes de prendas de importación, o simplemente argumentan que deben realizar un viaje de regreso y desprenderse de prendas por las tasas aduaneras o para cambiarlas por tequilas u otros obsequios.

El poder de los calós reside en su capacidad de persuasión y en el cómo proyectan la ilusión en la mente de los clientes. El imaginario de los payos alimenta la habilidad artística de los calós para generar estas ilusiones cuyo fin es alterar la percepción de los otros con el objetivo de vender el producto. $\mathrm{Y}$ a la vez se trata de la ilusión de parecer otra persona, el poder camaleónico, el secreto y la invisibilidad. Nos referimos no solo a una performance de una performance (la del piloto de avión o el periodista del New York Times "real"), sino a un proceso cultural transformativo que por medio de actos físicos y corporales construye identidades, relaciones y estatutos en base a la alteridad, y que emplea la facultad de copia, de imitación, para armar modelos, explorar diferencias y "llegar a ser otro" -no literalmente-, incluso apropiarse del carácter y el poder de ese otro (Taussig, 1993: xiii). 
La interrelación entre lo cognitivo y lo sociológico construye las relaciones sociales dinámicas y las ideologías culturales de domesticación, poder y control respecto al payo, y se describe la conciencia de superioridad de los calós respecto de los payos (cfr. Stewart, 1997b, y la superioridad moral/cultural de los rom vlach húngaros; Piasere, 1991: 213 y ss, y el rechazo a la proletarización como "hegemonía de lo interno" entre los rom de Verona). El efecto de domesticación y encapsulamiento de los payos en categorías objetivas y prácticas tiene implicaciones más generales puesto que la superioridad no sería algo circunstancial sino que se construiría como una estructura social en la cual el payo, sobre el papel, no puede iniciar ideológicamente una relación de reciprocidad. Esta relación de reciprocidad no ha de reducirse a la manera como en Occidente se ha enfatizado la reciprocidad desde un punto de vista material, sino que se trata de una relación cultural con todos sus recursos equivalente a una ideología/cultura de la reciprocidad.

Por tanto, en las transacciones comerciales los calós también afirman y exhiben preferencias marcadas culturalmente y elementos de identificación nacional, y parecen señalar con ello afinidades interculturales. En este sentido, la mímesis-imitación es el reflejo de la flexibilidad y porosidad de la diferencia entre el yo y el otro, donde siempre se halla la "distancia" respecto a lo imitado (Taussig, 1993: xix). Ello implica que los calós tienen cuidado de no ser identificados como gitanos, afirmando que como españoles y comerciantes son personas que expresan relaciones de complementariedad económica, social y cultural con los mexicanos. Éste es un elemento cultural adaptativo que nos indica cómo el significado de la conciencia y atribución de significado a la "raza" y la cultura así como su negociación al exterior es producido en el intercambio y la interacción con los payos.

El caso de los calós mexicanos muestra que la afinidad intercultural, como actividad incorporada y como discurso reflexivo, es parte de la fabricación de los contenidos de la cultura, revelando que ésta se construye a base de haber absorbido, usualmente de manera imperceptible, elementos de otras culturas. En su relato de su periplo por varios países latinoamericanos uno de los informantes calós (varón, 55 años) señalaba: "hemos sido camaleónicos, adaptados a cada lugar. Si hemos visto algo bueno de ti, lo hemos absorbido". Esta absorción no se explica meramente como una mímesis no-consciente. Estudiar a los calós es entender elementos que en realidad no son exclusivos, son importados, y por ello, al ser provenientes de otros contextos constituyen préstamos, forzados o no, que se ensamblan con su tradición en un maridaje imperfecto, si bien, una vez adoptados empiezan a transformarse según los términos de las necesidades de las poblaciones locales.

Los calós mexicanos han creado una sociedad que ha sido pensada muy bien. El edificio de su comunidad -y el de otras comunidades gitanas- no es económico sino social, 
puesto que crean y cultivan relaciones sociales. De hecho, no es muy habitual encontrar individuos calós que estén solos, y esta individualidad puede ser una marginación voluntaria o bien impuesta por la familia o la comunidad.

Por diferentes vías, los discursos y las prácticas cotidianas de importancia estratégica para los calós mexicanos representaban una vía mejorada para su inserción en la sociedad mexicana y, por extensión, la modernidad. A causa de que las sociedades, los poderes, los sujetos, construyen diversas nociones de «modernidad» al describir sus identidades, la noción misma debería conceptuarse como parte de un juego de lenguaje, a lo Wittgenstein, en lugar de una realidad objetiva, ya que funciona como concepto general (como imagen) que condiciona la explicación de la realidad, una vez se seleccionan los aspectos comunes de dichos fenómenos (sociedades, poderes, sujetos). A causa de que los contextos donde la "modernidad" se enuncia son dispares, la unidad temporal que se propone cuando los calós mexicanos refieren a que ellos se convirtieron, en su epopeya americana, en un grupo "más avanzado" que los gitanos y los payos, primero, de un Estado franquista atrasado, y posteriormente, del Estado español democrático, no debería darse por sentada. Las prácticas reales y pragmáticas, de complejas negociaciones y cruces de fronteras, a lo Barth, que este grupo de gitanos puso en juego, reflejaba su compromiso con la historia y las posibilidades abiertas, y su compromiso con la modernidad.

Los calós mexicanos son creativos culturalmente, y esto es una obviedad puesto que, como seres humanos, podemos construir la sociedad que queramos. La particularidad reside en que observamos en ellos una distinta apreciación de los fenómenos a partir de una enculturación desde prejuicios diferentes a los de sociedades de su entorno. Con ello expresan un tipo de cosmovisión local susceptible de influenciar el pensamiento antropológico. 


\section{REFERENCIAS BIBLIOGRÁFICAS}

Asséo, Henriette (1994) Les tsiganes. Une destinée européenne. Paris: Gallimard.

Brubaker, Rogers (2004) Ethnicity without Groups. Cambridge: Harvard University Press.

Cooper, Frederick (2005) Colonialism in Question. Theory, Knowledge, History. Berkeley: University of California Press.

Firth, Raymond (1975) "An Appraisal of Modern Social Anthropology". Annual Review of Anthropology 4, pp. 1-25.

Firth, Raymond (1981) Hombre y cultura. La obra de Bronislaw Malinowski. México D. F.: Siglo XXI.

Fraser, Angus (2005) Los gitanos. Barcelona: Ariel.

Friedman, Jonathan (2001) Identidad cultural y proceso global. Buenos Aires: Amorrortu Editores.

Gallissot, René (2000) "Identité/identification". En René Gallissot, Mondher Kilani y Annamaria Rivera (coords.) L'imbroglio ethnique en quatorze mots clés. Laussane: Payot, pp. 133-143.

García, Mary Ellen (2005) "Influences of Gypsy caló on Contemporary Spanish Slang". Hispania 88 (4), pp. 800-812.

Goffman, Erving (1981) La presentación de la persona en la vida cotidiana. Buenos Aires: Amorrortu.

Gomes, Ana María (1998) "Vegna che ta fago scrivere”. Etnografia della scolarizzazione in una comunità di Sinti. Roma: CISU.

Herzfeld, Michael (2001) Anthropology. Theoretical Practice in Culture and Society. Oxford: Blackwell.

Holy, Ladislav y Stuchlik, Milan (2006) "Anthropological Data and Social Reality". En Henrietta Moore y Todd Sanders (eds.) Anthropology in Theory: Issues in Epistemology. London: Blackwell, pp. 159-168.

Houseman, Michael (1994) "Etude des Tsiganes et questions d'anthropologie". Etudes Tsiganes 2, pp. 11- 18.

Lagunas, David (2005) Los tres cromosomas. Modernidad, identidad y parentesco entre los gitanos catalanes. Granada: Comares.

Lagunas, David (2010) Segregar, producir, contestar. Una etnografía con gitanos andaluces de La Mina. Madrid: Entimema. 
Leblon, Bernard (1990) Mossa, la Gitane et son destin: témoignages d'une jeune Gitane sur la condition feminine et l’évolution du monde gitan. Paris: L'Harmattan.

Liégeois, Jean-Pierre (1973) “La kris”. Études Tsiganes 3, pp. 31-46.

Maine, Henry Sumner (1893) El derecho antiguo. Madrid: Escuela Tipográfica del Hospicio.

Maine, Henry Sumner (1900) Las instituciones primitivas. Madrid: La España moderna.

Okely, Judith (1997) "Some Political Consequences of Theories of Gypsy Ethnicity. The Place of the Intellectual". En Allison James, Jenny Hockey y Andrew Dawson (eds.) After Writing Culture. Epistemology and Praxis in Contemporary Anthropology. London: Routledge, pp. 224-243.

Piasere, Leonardo (1985) Mare Roma. Categories humaines et structure sociale. Une contribution à l'ethnologie tsigane. Paris: Etudes et documents balkaniques et méditerranées.

Piasere, Leonardo (1991) Popoli delle discariche. Saggi di antropologia Zingara. Roma: CISU.

Piasere, Leonardo (1994) “Les Tsiganes sont-ils 'bons à penser” anthropologiquement?”. Études Tsiganes 4(2), pp. 19-38.

Piasere, Leonardo (1995) Comunità girovaghe, comunità zingare. Napoli: Liguori.

Piasere, Leonardo (1996) Italia Romani. Roma: CISU.

Piasere, Leonardo (1999) Un mondi di momdi. Antropología della culture Rom. Napoli: L'Ancora.

Piasere, Leonardo (2004) I rom d'Europa. Una storia moderna. Bari: Laterza.

Rao, Aparna (1987) “The Concept of Peripatetics: An Introduction”. En Aparna Rao (ed.) The Other Nomads: Peripatetic Minorities in Cross-Cultural Perspective. Köln: Böhlau Verlag, pp.1-32.

San Román, Teresa (1994) La diferència inquietant. Velles i noves estratègies culturals dels gitanos. Barcelona: Altafulla.

Stewart, Michael (1997a) “The Puzzle of Roma Persistence. Group Identity without a Nation". En Thomas Acton y Gary Mundy (eds.) Romani Culture and Gypsy Identity. Hatfield: University of Hertford Press, pp. 82-96.

Stewart, Michael (1997b) The Time of the Gypsies. Oxford: Westview Press. 
Stewart, Michael (2010) "Introduction". En Michael Stewart y Marton Rovid (eds.) Multi-disciplinary approaches to Romany studies. Selected papers from Participants of Central European University's Summer Courses 2007-2009. Budapest: Central European University, pp. 1-9.

Tambiah, Stanley J. (1995) Rituali e cultura. Bologna: Il Mulino.

Taussig, Michael (1993) Mimesis and Alterity; A Particular History of the Senses. London: Routledge.

Terradas, Ignasi (2004) "La contradicción entre identidad vivida e identificación jurídicopolítica”. Quaderns de l'Institut Català d'Antropologia 20, pp.63-79.

Turner, Victor (1985) “The Anthropology of Performance”. En Victor Turner, Edith L. Turner y Edith L.B. Turner (eds.) On the Edge of the Bush. Anthropology as Experience. Tucson: University of Arizona Press, pp. 177-204.

Weyrauch, Walter Otto y Bell, Maureen Anne (1993) "Autonomous Lawmaking. The case of the Gypsies". The Yale Law Journal 103(2), pp. 323-399.

Williams, Patrick (1984) Mariage Rom: une cérémonie de fiançailles chez les Rom de Paris. Paris: L'Harmattan.

Williams, Patrick (1994) “Introduction”. Études Tsiganes 4(2), pp. 4-7.

Williams, Patrick (1996) "Ethnologie, déracinement et patrimoine. À propos de la formation des traits culturels tsiganes". En Daniel Fabre (ed.) L'Europe entre cultures et nations. Paris : Éd. de la Maison des Sciences de l'Homme, pp. 283-294.

Williams, Patrick (2011) “Une ethnologie des Tsiganes est-elle possible?”. L'Homme 197, pp. 7-23.

Winch, Peter (1994) Comprender una sociedad primitiva. Barcelona: Paidós. 